\title{
The Influence of the New Generation of Information Technology on Management Accounting Reform
}

\author{
Fengzhou Wang \\ School of Business Administration \\ JIMEI University \\ Xiamen, China \\ fzhwang@jmu.edu.cn
}

\author{
Yongqi Song \\ School of Finance and Economics \\ JIMEI University \\ Xiamen, China \\ 1577701487@qq.com
}

\begin{abstract}
The rapid development of cloud computing, big data, internet of things, mobile Internet and other new generation of information technology has a profound influence on the development of management accounting. Based on the review of the domestic related research literature, the paper puts forward the main changes of the new generation of information technology to promote the management accounting reflected that promoting the innovation of management accounting theory and method, helping to improve the construction of management accounting information system, putting forward new requirements to the internal control of enterprises, promoting the role change of management accounting personnel and so on.
\end{abstract}

Keywords-the new generation of information technology; accounting management; reform

\section{INTRODUCTION}

Since the beginning of this century, the Internet of things, cloud computing, big data, mobile Internet and other new generation of information technology go deep into every field of economy and society at an unprecedented speed, and cause great changes in business model, transaction mode, integration of resources, management activities and so on. With the further development of a new generation of information technology, and comprehensively promote the construction of the management accounting system, how to correctly and fully understand that the new generation of information technology has a significant and far-reaching impact on the management of accounting, which will have an important practical significance to accelerate the profound change of management accounting and management accounting system construction.

\section{AN OVERVIEW OF THE NEW GENERATION OF INFORMATION TECHNOLOGY}

The revolution of Internet of things, big data, cloud computing, mobile Internet and other representative of the new generation of information technology constantly creates new technology, new products and new applications, which is becoming a new driving force for the development of the global economy. The combination of the new generation of information technology and management accounting is bound to bring new opportunities for the development and construction of management accounting. This paper mainly introduces the Internet of things, big data, cloud computing, mobile Internet and other new generation of information technology on management accounting change.

Internet of things through radio frequency identification (RFID), infrared sensors, GPS, laser scanners and other information sensing equipment, according to the agreed protocol, connects anything with the Internet, and exchange information and communication, which is a network to realize intelligent identification, positioning, tracking, monitoring and management[1]. Internet of things achieves the effective connection of all items and the network, so that the Internet has penetrated into all aspects of our lives. At the same time, the Internet of things has three basic characteristics of comprehensive perception, reliable transmission and intelligent processing [2]. Big data is a data set, which the consumption time of using a variety of common software tools to capture, manage and process data is more than the tolerance time. Generally speaking, the big data has four characteristics: volume, variety, velocity and value [3]. Cloud computing is a model, which customers through fast and convenient network get into configurable computing resources pool, and achieve rapid delivery, on-demand expansion, take as needed, chargeby-byte and other forms of service. And the main features of accounting cloud computing include: (1) providing services with the ability of accounting calculation; (2) network access; (3) aggregating resources into the pool; (4) elastic expansion; (5) service can be measured[4]. Mobile Internet is a Internet services with a data interface of mobile network, including mobile terminals, mobile networks and application services [5]. Compared to the traditional Internet, mobile Internet has the characteristics of mobility, openness, convenience, intelligence, personalization and so on. With widely application of the smart phones and other devices, mobile Internet technology has a profound impact on the traditional accounting services.

\section{A REVIEW OF THE INFLUENCE OF THE NEW GENERATION OF INFORMATION TECHNOLOGY ON MANAGEMENT ACCOUNTING}

With the rapid development of a new generation of information technology, there have been extensive discussions 
by domestic and foreign scholars about the influence of cloud computing, big data, mobile Internet, Internet of things and other information technology on management accounting. The current research situation is mainly reflected in the following three aspects.

\section{A. The New Generation of Information Technology Changes the Scope and Mode of Data Processing, Thus Changing the Way of Management Accounting and Improving the Efficiency of Management Accounting.}

Lei Xiong (2014) proposed that cloud computing benefit the construction of management accounting information, and will help enterprises to reduce costs and achieve internal coordination, so as to improve the efficiency of internal management of enterprises. [6]. Yahu $\mathrm{Xu}$ and Ting Wang (2015) believed that management accounting work by using large data has produced a profound reform in data collection, data storage, data processing, data analysis and other aspects of the management accounting[7]. Hui Wu and Fang Liu (2015) pointed out that big data technology makes management accounting more emphasis on forecasting functions, and the analysis from results oriented to process oriented, thus non-financial indicators will be more used by management accounting work and the "management" of management accounting will become more sophisticated management [8]. Mobile Internet, Internet of things produces a large collection of data which is difficult to deal with, but the emergence of large data, cloud computing and other information technology provides a guarantee for the management accounting from a higher level to deal with these large data.

\section{B. The new Generation of Information Technology Broadens the Data Sources of Management Accounting and Enriches the Work Contents of Management Accounting.}

Jian Wang and Xiaohu Li (2010) believed that the Internet of things solves the problem of accounting data source, "clears" the production cost of the enterprise and promotes the realization of real-time accounting information system, which ensures the authenticity and reliability of the management accounting information [9]. Xu Chen and Liang Fan (2015) pointed out that large-scale application of mobile Internet technology has brought a lot of big data set which is hard to concentrate and deal with, especially the large amount of unstructured and semi-structured data. But cloud computing allows companies to easily access the external data possibly, which greatly expands the source of management accounting data needed[10]. Rongbin Zhou (2015) argued that with the arrival of the "Internet + " era, the service object of management accounting is changed from serving for the enterprise internal at the beginning to gradually serving for the whole value chain which serves internal and external customers as the center [11]. The development of a new generation of information technology changes the traditional business model and resource integration model, and expands the scope of service of management accounting to a certain extent, so that the management accounting work is extended from the enterprise internal management to the whole value chain management, from the tactical level to strategic layer, from profit maximization to the sustainable value realization of enterprise.

\section{The New Generation of Information Technology Has} Brought the New Problem to the Management Accounting, Which the Information Storage Space is Insufficient, the Information Security is Not Guaranteed and so on.

Yibin Gao (2015) proposed that with the effective application of new technologies such as mobile Internet, cloud computing, how to effectively solve the problem of information security and other issues, which will become an important practical problem faced by various units and government regulators [12]. Yunjiang Geng and Xiaoxiao Zhao (2015) believed that with the emergence of big data management accounting will be faced with the problem of management accounting information storage space, information security and other issues[13]. Big data, cloud computing and other information technology makes the enterprise has more efficient real-time data processing capability, the combination of the mobile Internet and cloud applications makes mobile office become possible, but how to ensure the information security of enterprises through legitimate and lawful means, which will become a major problem in the enterprises to pay attention to.

\section{THE INFLUENCE OF THE NEW GENERATION OF} INFORMATION TECHNOLOGY ON MANAGEMENT ACCOUNTING REFORM

\section{A. Promote the Innovation of Management Accounting Theory and Method.}

In fact, compared to the traditional management accounting, on the one hand, with the development of Internet of things, mobile Internet and other new generation of information technology, the large amounts of unstructured data exists in documents, audio and video, pictures, weblog and other applications of social networks, e-commerce, Internet of things, due to the complexity and variability of these data that the traditional management accounting data processing technology in the structure, size and processing requirements cannot be achieved, which caused a great impact on the traditional management accounting work. On the other hand, the network information technology reduces the cost of the information exchange between enterprises, and cloud computing technology make the various enterprises through the virtual organization form realize resource sharing and resource allocation, so that the business environment, business model, organizational structure and management methods have undergone radical innovation.

With the development of networking, cloud computing, big data and other new generation of information technology, the enterprise can not only acquire these massive external structured and unstructured data, but also make the management accounting obtain strong technical support in the storage and processing of the data. There is an urgent need for management accounting to form a new theory, method and procedure system, which is different from the traditional management accounting. Therefore, with the new generation of information technology as the support, set up the new 
thinking of open integration of resources, achieve the "cloud operation" of the information transmission and processing, and make full range of management accounting innovation from the construction of the basic theoretical framework, the application of technical methods to research methods and perspectives, management accounting culture construction, etc. so as to promote the construction of management accounting theory system and guidance system with Chinese characteristics. At the same time, the Internet of things, big data and other advanced information technology has data collection, storage, processing function, which provides strong technical support for the construction of the management accounting case base and the innovation of the research methods of the research results, and it will play a complementary role in the construction of management accounting theory system and guidance system and provide the best practice basis for the management accounting advisory services.

\section{B. Help to Improve the Construction of Management Accounting Information System.}

At present, for the mainstream enterprise resource management system or financial software, there is no independent system of management accounting, which is dispersedly integrated into the other subsystems [14]. But the effective integration and coordinated development of the management accounting with the principle of innovation mechanism and the new generation of information technology driven by innovation will provide favorable conditions for the construction of management accounting information system.

About data collection of management accounting information system, for paper documents, we can use OCR (Character Recognition Optical) technology to identify and acquire all kinds of text and picture information on paper documents. At the same time, we can use the Internet of things technology to realize intelligent identification, location, tracking, monitoring and management of data on the Internet. So it can be targeted to a large number of structured and unstructured information from the paper documents and the Internet, and input it to the management accounting information system for processing. About data storage problems of management accounting information system, cloud computing can completely eliminate the "information island" effect, which has "resource sharing, rapid delivery, extend at any time, take as needed" and other characteristics. The construction of management accounting information system based on cloud computing, which can not only enable enterprises to achieve data storage in PB level, but also consistent with the change stage in management accounting, real-time decision-making and so on, provides support for enterprises to establish a financial information sharing platform. About the data processing of the management accounting information system, using Analytical Processing On-Line (OLAP) and data mining technology for data processing and analysis, we can greatly enhance the management of accounting work refined and reliability. Based on the cost-benefit principle, fast acquisition and analysis of data in the information system make the management accounting been realized a transformation from results oriented to process oriented, so as to provide more timely data support for the decision-making of enterprises, and help enterprises to forecast, control and post evaluation.

At present, the key technology of large data, cloud computing, software has not yet established a unified standard system. Thus, between each subsystem of management accounting information system and industry supervision platform, it needs to build a unified data standards and data interface for cross platform transfer and effective use of management accounting data, and to give full play to penetration of a new generation of information technology on management accounting. And the development of Internet of things technology provides a strong technical support for the standardization of management accounting information system. Such as Extensible Business Reporting Language (XBRL), it is the latest application of the results of Internet of things technology in the management accounting, which also provides favorable conditions to reduce the cost of management accounting information.

\section{Put forward New Requirements to the Internal Control of Enterprises.}

Internet of things, big data, cloud computing and other information technology helps enterprises to collect a huge amount of information, which contains a large number of confidential information and business secrets about enterprises, customers, employees and other things. At the same time, with the construction of the management accounting information system, a large amount of information stored in the information system will face the risk of being attacked by the network as well as the illegal invasion. Therefore, how to prevent the data damage and the leak of information put forward new requirements for the internal control of enterprises.

Enterprises should strictly follow the three objectives of internal control and the five major factors, and improve the internal control system construction. Firstly, enterprises should strengthen enterprise culture construction to create a good environment for information security control. Secondly, it is important to fully do a good job of risk assessment in advance and to formulate corresponding risk response plan of information security. Thirdly, enterprises should strict examination and approval, authorization, confirmation, review and other working procedures, and through the information source authentication, access control, data encryption and other information technology guarantee the security of management accounting information system security in the control activities. What's more, it is necessary to strengthen the effective communication between the superior and subordinate, which can prevent the major decision-making errors in the process of information transmission caused by data damage and leakage. Finally, in order to revise and improve the internal control system, enterprises should evaluate the quality of internal control after the event. At the same time, the development of Internet of things and other modern information technology will "clear" the business conditions, production cost, budget management and other accounting information, which not only ensures the authenticity of the management of accounting data, but also 
provides a powerful technical tool for the supervision function of the internal control of enterprises.

\section{Promote the Role Changes of Management Accountant.}

A new generation of information technology serves "intelligent" as the starting point, promotes the transformation and upgrading of management accounting functions, helps people to get rid of the repetitive and transactional information management work, improves the efficiency of management accounting work, and provides support for management accountants to have more time and to do enterprise decisionmaking, thus the direct communication between people and the intellectual communication is also very important. At the same time, the advanced information technology forms the organization form and communication mode of open cooperation between enterprises. Thus, management accountants should not only pay attention to the internal management information, but also analyze the information state of whole value chain, such as the advantages and disadvantages of the competitors in the same industry, as well as the business situation and the current situation of the funds of the enterprise's suppliers and the potential user needs of the enterprise.

As a result, this new change has impacted on the position function of traditional management accounting, which urgently needs the role change of management accountant. This new role change not only requires the management accountants to master relevant management accounting techniques and professional financial knowledge, but also needs the management accountants to change the thinking, reserve more business management knowledge, have the ability to analyze the data required for decision making, develop good interpersonal skills, and study the application of information technology such as cloud computing, big data, mobile Internet, Internet of things etc. in management accounting. Enterprises should increase capital investment to achieve the full training of management accountants. In the face of the development of a new generation of information technology, it is necessary to establish a full range of management accounting talent support system.

\section{SUMMARY}

The rapid development of the Internet of things, cloud computing, big data, mobile Internet and other advanced information technology, which brings a variety of opportunities and challenges to the development of management accounting. But we must realize that the new generation of information technology will be the next important productive force to promote the rapid development of the national economy. We should firmly grasp this good opportunity, profoundly realize the influence of the new generation of information technology on management accounting reform, seize the opportunity and meet the challenge. So, it will fully promote effective integration of the big data, cloud computing, mobile Internet, Internet of things and other advanced information technology and management accounting, so as to better play the role of management accounting.

\section{REFERENCES}

[1] Subin Shen,Quli Fan,Ping Zong,Yanqin Mao and Wei Huang."Research on the architecture and related technologies of Internet of things," Journal of Nanjing University of Posts and Telecommunications (NATURAL SCIENCE EDITION), 2009,06, pp.1-11. (In Chinese).

[2] Qibo Sun, Jie Liu, Shan Li, Chunxiao Fan and Juanjuan Sun."The Internet of things: concept, architecture and key technology research, " Journal of Beijing University of Posts and Telecommunications, 2010,03, pp.1-9. (In Chinese).

[3] Xiaofeng Meng and Xiang Ci."Big data management: concept, technology and challenge," Computer Research and Development, 2013,01, pp.146-169. (In Chinese).

[4] Jinye Xu."Accounting Cloud Computing: the brain intelligence of Internet of things system,” Accounting Friends, 2012,24, pp.90-91. (In Chinese).

[5] Jun Wen, Sifeng Zhang and Taozhu Li."Current situation and trend of mobile Internet technology development," Communication Technology, 2014,09, pp.977-984. (In Chinese).

[6] Lei Xiong." Preliminary study on the application of cloud computing in the management accounting information," Communication of Finance and Accounting, 2014,34, pp.99-100. (In Chinese).

[7] Yahu Xu and Ting Wang."The change of management accounting in the era of big data," Communication of Finance and Accounting, 2015,16, pp.13-15. (In Chinese).

[8] Hui Wu and Fang Liu. "Impact of big data technology on management accounting,” Finance and Accounting, 2015,14, pp.45-47. (In Chinese).

[9] Jian Wang and Xiaohu Li."Study on the Internet of things boosting accounting information change," Communication of Finance and Accounting, 2010,22, pp.119-120. (In Chinese).

[10] Xu Chen and Liang Fan."The concept of management accounting information under mobile Internet-based on the cloud computing platform,” Accounting Friends, 2015,19, pp.80-82. (In Chinese).

[11] Rongbin Zhou."How to promote the application of management accounting in "Internet plus" era," Audit and Financial Management, 2015,09, pp.41-42. (In Chinese).

[12] Yibin Gao."Seize the development trend of the Internet to meet the era of big accounting," Finance and Accounting, 2015,17, pp.6-7. (In Chinese).

[13] Yunjiang Geng and Xiaoxiao Zhao."Opportunity, challenge and response to management accounting in the era of big data," Accounting Friends, 2015,01, pp.11-14. (In Chinese).

[14] Yongmei Zhang and Ying Yu.“ The design of enterprise management accounting framework in "Internet plus" era,” Accounting Friends, 2016,03, pp.126-129. (In Chinese). 